\title{
Interaction Design of Office Supplies Based on GTD
}

\author{
Yurong Gan*, Aijuan Jiang, Li Heng \\ Departments of Engineering, University of Nan Shan, Yantai, China
}

\begin{abstract}
In daily study and work, there are some people who complain about procrastination and how to change from an ill-adapted procrastination patient to the adaptive procrastination to improve the efficiency of work by using procrastination. This paper studies the procrastination crowd, analyzes the cause of procrastination anxiety, and puts forward a method based on management time-GTD (Getting Things Done) designs a set of office supplies design combining software and hardware from the point of view of product design. Hopefully, through the core principles of GTD: collection, collation, organization, review, and execution of a series of steps to procrastinate patients at a certain stage Solve or alleviate the bad factors caused by procrastination in order to improve the efficiency of the work.
\end{abstract}

\section{Introduction}

According to statistics, $70 \%$ of college students have procrastination problems, and $50 \%$ of them want to solve their own problems of procrastination.Their academic achievement was seriously affected by the delay ${ }^{[1]}$. Procrastination does not have a typical profile, with $25 \%$ of adults in the general population suffering from chronic procrastination. There are two types of arguments about procrastination: one is the traditional type of poor adaptability, in which behavior is inadvertently delayed despite known adverse risks to performance or personal comfort (passive procrastination); another is the type of adaptation, in which behavior is deliberately delayed as a means of enhancing motivation, but it is not detrimental to valuable results (active procrastination $)^{[2]}$.

Procrastination has become one of the social problems in China, and many people are anxious all the time because of personal management problems ${ }^{[3]}$. The basic message of procrastination is that procrastination is neither a bad habit nor a moral problem, but a psychological syndrome caused by fear, says Jane B. Lenora and M. Burka Yuen, in his book Procrastination: Why You Do It, What to Do About $\mathrm{It}^{[4]}$. Now people are faced with a variety of work pressure to delay the work, behind a number of extremely complex psychological reasons. The article hopes to focus on "how to solve On the stress of working life and anxiety caused by procrastination, a systematic personal management method "GTD" has been found.

\section{The concept of GTD}

David Allen, the well-known time manager, proposed a set of working methods called GTD, which was interpreted as "Getting Things Done." The core concept of GTD is to ask people to do things in certain order at any time.All things are removed from the brain at work, and anything that is thought to have not been done must be re-examined and cleaned up in an objective, reliable system or tool; Learn to use "execute, distribute, delay and release"to empty all work baskets,plan and subdivide tasks properly, guide people out of the planning and implementation of the quagmire, and warn people that the key to maintaining order is calm and relaxation. Work on a healthy and efficient path ${ }^{[5]}$.

GTD's main ideas are summarized as follows: Emptying the brain: the amount of space a thing occupies in the head is inversely proportional to the power of thought and control over it. Sort out all the things you need to do, store them one by one in a logical and reliable system, and then integrate and think about how to deal with them quickly. The brain spends too much time every day reminding people of what to do and what they haven't done, and it's bound to make people overburdened by thinking about things at the same time as they have to remember things in a mess, too much time every day to remind people what to do and what not to do. People should

*Corresponding author’s e-mail: 1272719385@qq.com 
free their brains from this thinking [5]. Project specificization: whatever the problem is, the question people want to ask is what to do next. Only in this way can people make specific plans so that they can grasp what should be done. So that when certain actions are taken at a given time, the best choice can be made and confidence in this choice can be made.

\section{The role of GTD}

In Reverse, Malcolm Gladwelll puts forward a very clear view "As the environment changes, some weaknesses can be transformed into strengths, while others see strengths as weaknesses." ${ }^{[8]}$ According to the above description, "execute" is in the last step of the operation step of GTD.In GTD, with the exception of what can be done in two minutes, all actions are divided into the next action list, the waiting list, and the future / maybe list. This is an advantage for those who have procrastinated, and using GTD's method of work can easily transform the anxiety of "procrastination" into an advantage of efficient use of time. This approach has the following advantages: Forcing yourself to reverse the exact time required for the work from the deadline to complete the task in the shortest possible time; Improving the quality of the work. Although not immediately starting to work, the brain is already thinking about solutions in the context of collecting, sorting, organizing, and reviewing, so the results tend to be more mature. Proper pressure increases creativity and inspiration, so creative work sometimes requires appropriate "procrastination".

So using the GTD operation, when a new task appears, don't rush to execute it, put things into the next step, because the specific requirements of the task and the conditions required to complete the task will change during the initial period of time. We can procrastinate properly until the dust settles before we start. It is an efficient working habit.

\section{The design of office supplies based on the GDT}

People working in the office need a tool to form habits of thought and create a work environment that helps them focus on strategic and tactical levels, ensuring that they don't miss anything that needs to be addressed, and that they don't miss a flash of inspiration. And adjust clear classification and arrangement, to achieve more active and effective work, form a better way of work norms. In the traditional design of office supplies, most of the pursuit simple and efficient route. People pay more and more attention to the function and efficiency of public goods. The current situation of the office supplies market is not consistent with the needs of office personnel, people are eager to have a pleasant experience in office supplies ${ }^{[9]}$.

\subsection{User model}

User model is a representative of similar user requirements. In order to express its requirements more vividly, the user model forms a concrete character as the carrier of the problem discussion. The user model carries the common characteristics of a certain class of users ${ }^{[10]}$. In this design, the user model is divided into two categories: the main character model and the secondary character model. The main character model is the main user group of the product, designed with the behavior and needs of such users as the direction of design [11], mainly including procrastination patients, young white-collar workers and graduates who are beginning to enter the workplace, who are in urgent need of a tool. Let them work more orderly and efficiently.

In addition to the main requirements, there are some specific requirements for the secondary personage model. A secondary person model refers to a group that has the same needs next to the main character model and uses the product because it meets its own needs to a certain extent.

\subsection{Design positioning}

In view of the above analysis, the article puts forward the product positioning as follows: adopting the combination of software and hardware, in addition to recording transactions inside the software, we can collect information at any time through hardware and connect mobile phone APP to organize and organize; implement the list office software based on GDT system. The working methods of GTD are presented in the form of APP, and the collection, organization, review and execution of transactions can be completed by using APP. The major user groups are graduates who are inexperienced in personal management or white-collar workers who enter the workplace to form good working habits, personal management, light team coordination. Software In addition to providing the GTD working methods of the system, the basic co-working functions should be provided. Through the collaborative function, meet the needs of the user in the team cooperation.

Based on the five steps of the GTD operation, the product information structure is designed according to the requirements of the user(Fig. 1). 


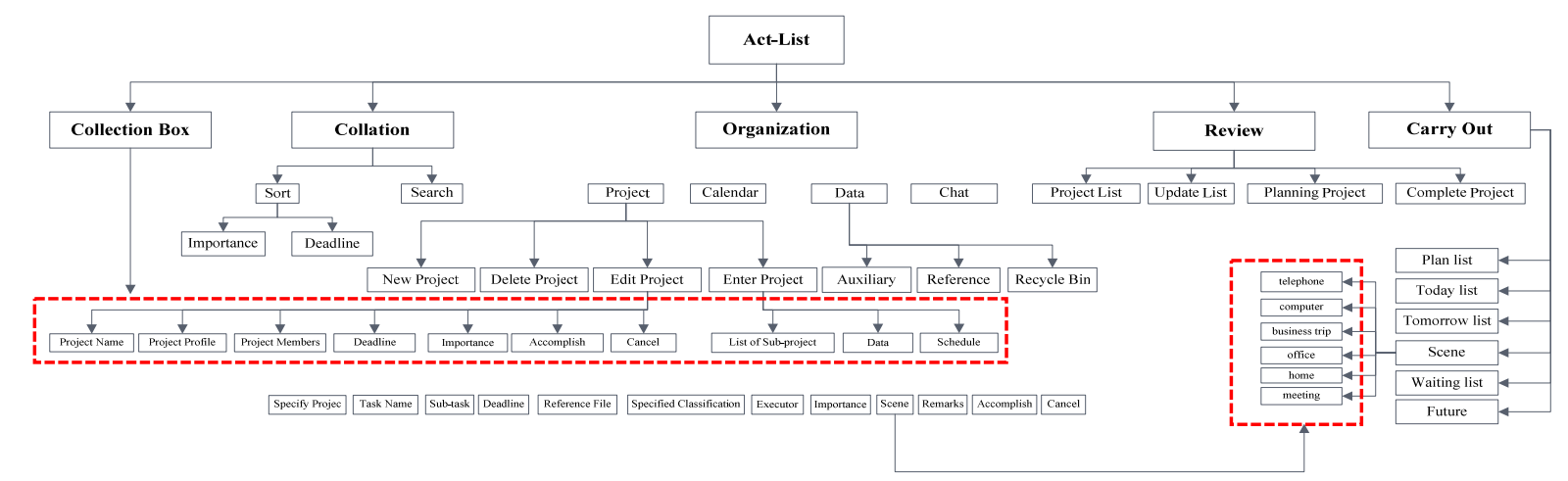

Figure 1. Product Information structure

\subsection{Collection tool design.}

The collection tool includes Act-List writing, Voice recorder(Fig. 2).The first step in the GTD is to collect everything you think of and store it in an objective container. Pen is the earliest recording tool of mankind. In ancient times, people carved text information on oracle bones and stones, recorded things with pen deep in human subconscious mind and any tool was a imitation of paper and pen.

Act-List designed for the subconscious, rethinking the pen, a collection tool that allows you to record and confirm written notes on paper. At the same time, it can be used to record the voice information anytime, anywhere, and digitize the voice message through the smart phone, and turn it into a list of actions that can be directly executed or can use reference materials and so on.

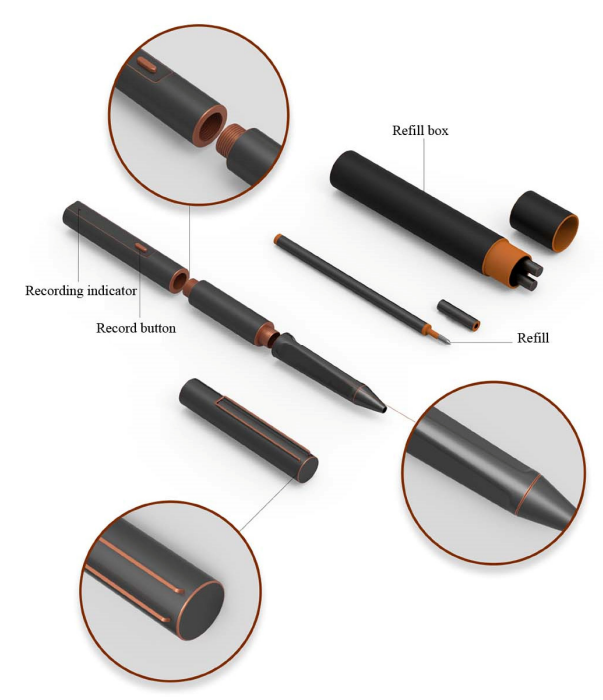

Figure 2. Act-List Writing Voice Recorder

\subsection{The design of APP interactive prototype diagram}

4.4.1. Collection Box. The collection box is used to record and store all pending and collected content(Fig. 3 ). The brain keeps track of a lot of unfinished things, which interferes with other things people want to think about and, in turn, reduces productivity. One of the main functions of the collection box is to clear the brain, store all the clutter in the brain, focus on completing the current work, and then think about other things.

Voice Quick Recording: click on the lower right-hand collection box to quickly record ideas and transactions in your brain for further processing. Keyboard input record content: when it is not convenient to use voice or text to organize the language, you can enter the text through the keyboard and record it in the collection box. Click the add button at the bottom of the screen, you can add attachments, after editing, click the send button, you can edit the contents, save in the collection box. 


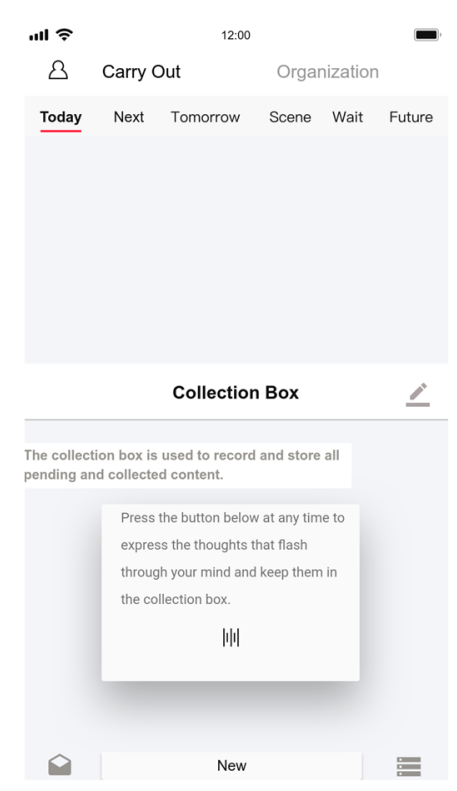

Figure 3. Collection Box

4.4.2Organization, Collation and Review. The organization means that the location of the transaction matches its meaning, on the one hand, it refers to the organization and arrangement, on the other hand, it means review and coordination(Fig. 4). If you decide
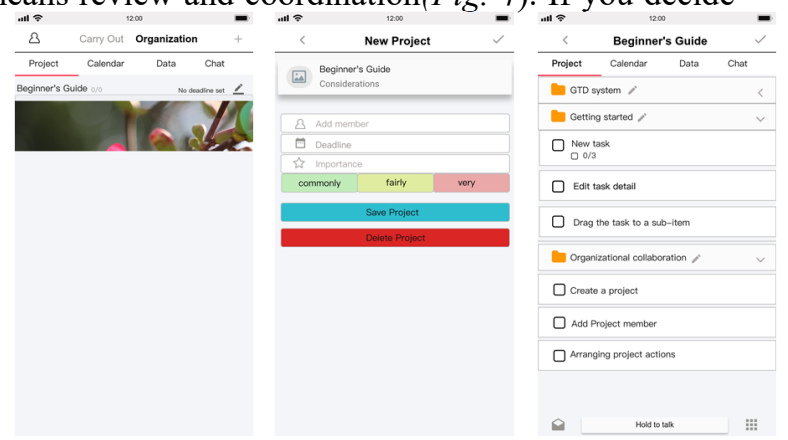

Figure 4. Organization

Data: all documents contain items, collection boxes, and all attachments to the operation. The attachment to each project is stored in the project support material. The Recycle Bin holds all deleted content in the completed task to view completed actions.

Chat list: after you create a new project, you can automatically create a new chat session by clicking on the top-right side of the project chat group.

Project: project is the basic unit of collaborative work. You can easily organize your day-to-day work to save something as a reference material and store it in the necessary place, this is organization. Organizational collaboration refers to working with a team to complete a project.
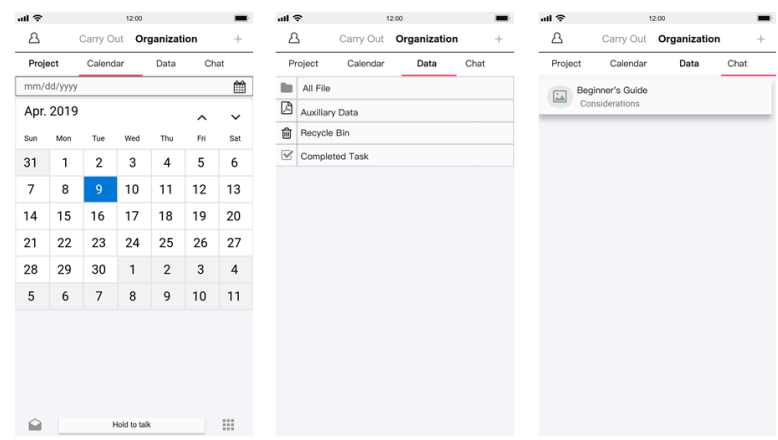

while supporting day-to-day collaboration among team members. Collaborate efficiently in project management, agile $\mathrm{R} \& \mathrm{D}$, product design, innovation management, strategic management, etc.

4.4.3Carry Out. The basic units of execution are actions, objectives, system classifications and methods. If you spend all your time on organization instead of doing it, all GTD systems are useless!(Fig.5). 


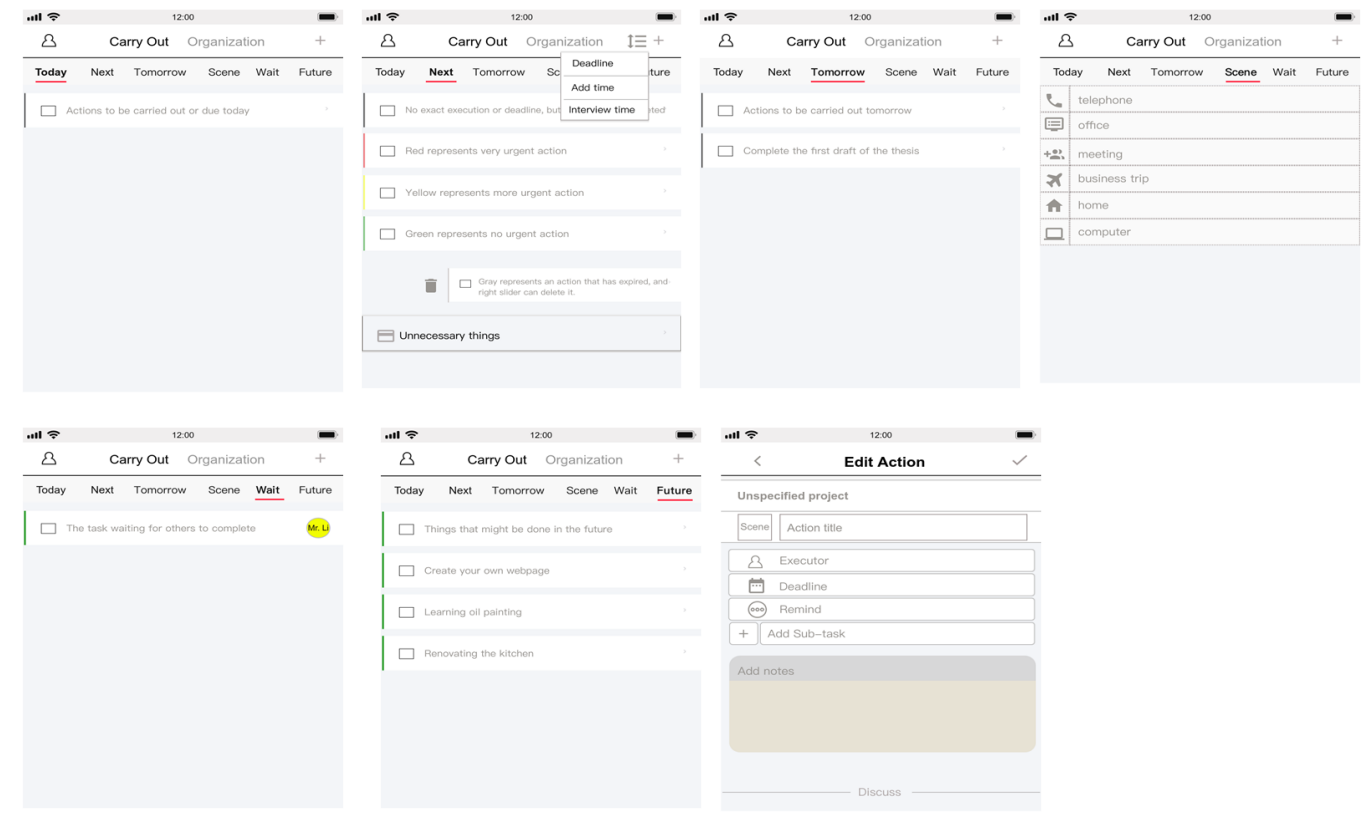

Figure 5. Carry Out

There are three situations in today's list of actions: actions that must be carried out at a fixed time today; actions that must be carried out throughout the day; and information that must be obtained. Today's Action list is based on schedules and actions that have not yet been implemented due today, and there is no quick add task bar. Next action list: the next action list records prompt information for all actions, can be quickly created through the bottom bar at any time, and can be sorted by deadline, add time, and access time.List of actions tomorrow: a list of actions that must be carried out tomorrow or not due tomorrow. Today there is likely to be a definite tomorrow action that can be created by creating the sub-bar quickly. Scene list: the scene list provides a quick way to filter executable actions through where the scene is located. Waiting list: waiting for other people to complete the action, at any time in the Quick create column to delegate new tasks to others. Future list: save work you don't want to do now, but you want to do it sometime in the future. Having such a list is not only useful, but inspiring.

\section{Conclusion}

The article originates from the procrastination phenomenon that can be seen everywhere in life, this kind of problem haunts many people. By using the GTD approach, people are exposed to the knowledge of self-management, processing information and improving efficiency. If they can adhere to these methods for a long time, they will make people more comfortable in an increasingly complex, nervous and irritable world.

From now on, set up facilities for individual organizations; create a viable and easy-to-access personal reference system (work and home); prepare a user-friendly planning manual that should contain a complete list of management projects; Allow yourself to make any changes aimed at improving your working environment. Hang pictures, buy pens, throw things, rearrange your workspace, and everyone can take better control of their work and life.

\section{References}

1. Bruce A. Fernie,Umran Y. Kopar,Peter L.(2018) Fisher,Marcantonio M. Spada. Further development and testing of the metacognitive model of procrastination: Self-reported academic performance.J. Journal of Affective Disorders, 240.

2. Jason Wessel,Graham L.(2019) Comparing effects of active and passive procrastination: A field study of behavioral delay.J. Personality and Individual Differences, 139.

3. Yan Yan(2016) Refusal of Procrastinationresearch on the design of procrastination information.D.Shanghai:Shanghai Normal University of Philosophy.

4. Jane

B.Burka,Lenora

M.Yuen.(2009)Procrastination

Psychology.China Renmin University Press,Beijing 
5. David Allen.(2016)Getting Things Done:The Art of Stress-free Productivity.Beijing:CITIC Press Group,Beijing

6. Guo

Heng,Juejie Gui.(2013)Information-based Means in Time Management.J.Chinese and foreign entrepreneurs, 32:173-174.

7. Lulu Yang. (2012)A Time Management Tool Based on Open Document Format.D.Tianjin University Malcolm

8. Gladwell.Reverse.Beijing:CITIC Press Group,2014,Beijing

9. Qiyue Zhang.(2015)Appeal Design in Office Supply.D.Shanghai:East China University of Science and Technology

10. Jing Dian.(2017)Different UI designers.Publishing House of Electronics Industry,Beijing

11. Alan Cooper.(2015)About Face 4: The Essentials of Interaction Design.Beijing:Publishing House of Electronics Industry,Beijing 